\title{
Environmental efficiency and policy change in China: A new meta-frontier non-radial angle efficiency evaluation approach
}

\author{
Malin Song ${ }^{\mathrm{a}}$, Shuhong Wang ${ }^{\mathrm{b}, \mathrm{c}, *}$, Liang Lei $^{\mathrm{b}}$, Li Zhou ${ }^{\mathrm{d}}$ \\ a School of Statistics and Applied Mathematics, Anhui University of Finance and Economics, Bengbu, Anhui 233030, PR China \\ b School of Economics, Ocean University of China, Qingdao 266100, PR China \\ ' Institute of Marine Development, Ocean University of China, Qingdao, 266100, PR China \\ ${ }^{\mathrm{d}}$ Faculty of Business, University of Greenwich, London, SE10 9LS, UK
}

\section{A R T I C L E I N F O}

\section{Article history:}

Received 18 July 2018

Received in revised form

15 September 2018

Accepted 23 October 2018

Available online 14 November 2018

Keywords:

Non-radial

Angle efficiency

DEA

Environmental efficiency

Meta-frontier

\begin{abstract}
A B S T R A C T
This study revised the non-radial angle model and set up the meta-frontier non-radial angle efficiency (MNAE) model. Moreover, an angle efficiency index was established in the MNAE model to reflect changes in the production decisions of decision-making units as a result of the external environment. The study conducted empirical analysis on data for 30 provinces in China from 2004 to 2015 . The results showed that the eastern area of China was sensitive to fluctuations in the world's economy and was able to quickly adjust production decision making; the western area lagged relatively behind in making changes, and the central area was not affected. Effects of international trade and foreign direct investment on the Shandong, Jiangsu, Fujian, Liaoning, Hunan, Henan, Jiangxi, and Sichuan provinces were significant and caused notable policy changes, which led to short-term resource waste and policy faults. This study also provides policy advice based on the results.
\end{abstract}

(c) 2018 Institution of Chemical Engineers. Published by Elsevier B.V. All rights reserved.

\section{Introduction}

With the acceleration of modernization, the ecological environment on which human beings rely has suffered unprecedented threats. Increase in discharge of hazardous pollutants has severely restricted social economic growth. In November 2015, relevant departments of 195 countries reached the Paris Agreement ${ }^{1}$ on multiple subjects, including emission objectives, relief, adaption, damages and losses, capital, technology, ability building, transparency, and global inventory, aiming to reduce losses and damages to the ecological environment caused by carbon emissions. China produced the most carbon dioxide $\left(\mathrm{CO}_{2}\right)$ emissions (Luo et al., 2017) and had the highest energy consumption in the world (BP, 2011), which mainly came from the country's manufacturing in five major industries (agriculture, manufacturing, construction, commerce, and transportation). Moreover, emission and consumption are still showing an increasing trend. Fig. 1 shows that there was an increase in industrial waste gas during the research years: it rose to 674.51 billion tons in 2011 and 694.19 billion tons in 2014. Dust

\footnotetext{
* Corresponding author at: School of Economics, Ocean University of China, Qingdao 266100, PR China.

E-mail address: shwang01@sina.com (S. Wang).

1 http://wenku.baidu.com/link?url=UsFMdSmCK6t-0XfbjvQdVjXJPelehw29LZSF8BF2 mH2wiB3DB3ahGFjI17ijcejKksRLTW4X0IJK0JoFngiBPrXNWfg6_
}

emission also reached its peak in 2014. According to the National Bureau of Statistics of China (2016), in 2014, gross output of the industrial sector accounted for $36 \%$ of China's gross output, while its energy consumption accounted for more than $73 \%$ of China's total energy consumption (excluding residential consumption). In other words, energy intensity was twice the national level.

The 2013 China Human Development Report written by the United Nations Development Program and the Institute for Urban and Environmental Studies China Academy of Social Sciences points out that the Chinese economy is in a critical period of urbanization. Its traditional industrial structure is rigid and energy demands are high, and this is difficult to change in the short term. Therefore, the Report of the 19th National Congress of the Communist Party of China specially put forward that green and sustainable development should be required to satisfy the ever-growing demand to maintain the ecological environment. The public is paying more and more attention to coordinated development between environmental protection and economic growth and plays an increasingly important role in environmental governance decisions (Do et al., 2009; Glucker et al., 2013).

As per the greenhouse gas emission control objective, the Chinese government has set the target of $\mathrm{CO}_{2}$ emission per unit of gross domestic product (GDP) in 2020 as $18 \%$ less than that in 2015 . In recent years, many provinces have adopted this $18 \%$ target to save energy by implementing the appropriate measures. However, judging from the process, several provinces such as Jiangsu, Zhejiang, 


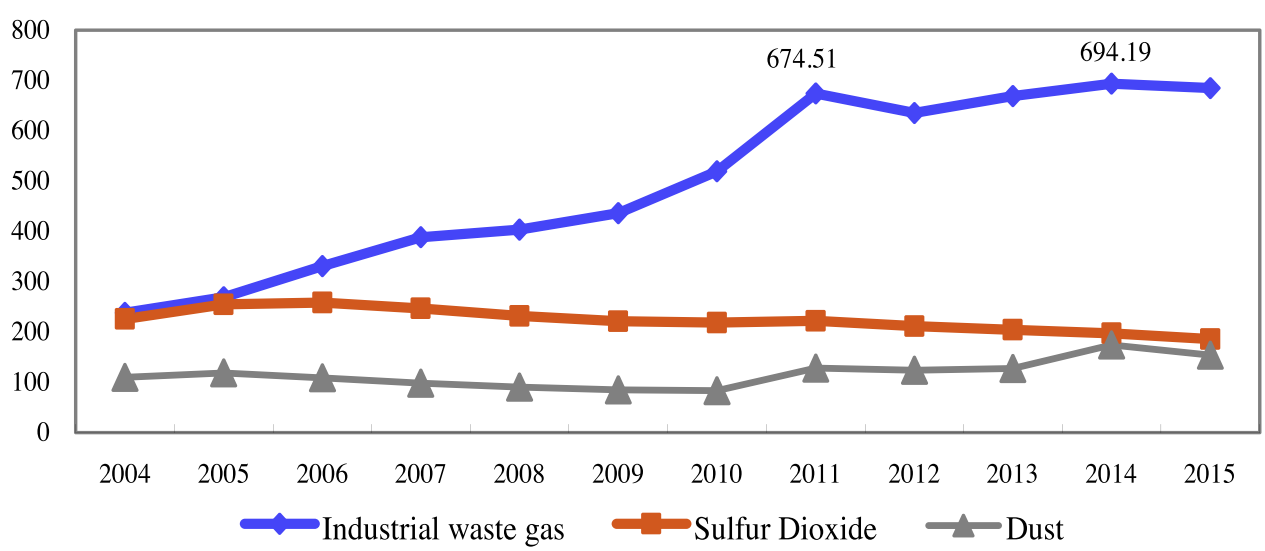

Fig. 1. Industrial pollution emission (billion tons).

Data Source: National Bureau of Statistics of China (NBSC), China Statistical Year Book, 2005-2016.

Hebei, and Shanxi have implemented some uncommon energysaving and emission reduction measures, such as power cutting and stoppage of work and production, to achieve this objective. Moreover, other provinces that had further energy-saving potential lost their impetus for energy saving. Therefore, a sweeping approach to manage energy saving and emission reduction without considering the disparity among different areas will definitely result in waste and low-utilization efficiency of resources. Hence, one must consider the trend and potential of economic growth of not only one area but also the overall national pathway to ensure a winwin situation as regards economic growth and carbon emission reduction.

Data envelopment analysis (DEA) is an effective tool to calculate relative efficiency, and it has been applied widely since its development (Cook and Seiford, 2009). Based on the DEA, an evaluation approach that considers environmental performance has gradually became one of the best internationally recognized methodologies in the field of environmental performance (Song et al., 2012). It also plays an important role in evaluating environmental governance decisions. The emerging non-homogeneity problem in recent years in evaluating environmental issues has presented new challenges in the application of the DEA method in environmental governance. By default, the DEA model assumes that decision-making units (DMUs) have exactly the same external environments, input and output indexes, etc. However, in an actual production process, such assumption is often difficult to realize (Haas, 1998; Saen, 2007; Saen et al., 2005). However, if we do evaluate with such an assumption of homogeneity among DMUs, the DMUs may not improve in some situations, which will have significant negative influences on the evaluation and enactment of management decisions. In the application of DEA, scholars have increasingly focused on this nonhomogeneity problem as an important research direction; see, for example, Feng and Wang (2017) and Tapia et al. (2017).

The purpose of this study is to explore the evolution of historical energy efficiency, reasons for energy inefficiency, and provincial energy saving potential during the period of 2004 to 2015 . We adopt the meta-frontier slack-based measurement (SBM) model that considers regional heterogeneity. Then, we decompose measurement results from the aspects of technology contribution, technology gap, management, and scale efficiency. Based on this, we include differences between the regional optimum and overall optimum as well as differences between the long-term optimum and shortterm optimum into our model to set up an angle meta-frontier SBM model. Thus, we can effectively address the shortcomings of the original radial evaluation model. After modeling, we measure the potential of every area in China as regards energy saving and the corresponding improvement objectives.

The remainder of this paper is structured as follows. Section 2 presents the literature review. Section 3 describes the methodol- ogy used, and section 4 presents the data and descriptive statistics. Section 5 presents the empirical results and discussion, and section 6 provides the conclusions.

\section{Literature review}

Many scholars abroad have researched the evaluation of energy efficiency. For example, Honma and Hu (2008) evaluated energy efficiency in Japan. Shi et al. (2010) found that the average performance of the eastern coastal areas in China was higher than that of the central and western areas through the evaluation of industrial efficiency of every province in China during 2000 and 2006. Li and Lin (2015) measured the energy efficiency performance with $\mathrm{CO}_{2}$ emissions for 30 provinces in China during 1997-2011. Lin and Yang (2014) and Lin and Zheng (2017) evaluated the energy efficiencies of China's power and paper industries; Guo et al. (2017) analyzed the energy efficiency of 30 provinces in China.

However, these studies have a common problem: they did not consider non-homogeneity among DMUs. According to Dyson et al. (2001), DMUs can be considered as homogeneous and DEA environmental efficiency can be evaluated only if the following three conditions are met: DMUs have the same technological level; DMUs have the same input and output indexes; and DMUs are in the same environment. When evaluating non-homogeneous DMUs on the same frontier, some DMUs may not be able to improve in the planned direction. Hence, the evaluation results of these studies are unsatisfactory when judged by the standard of Dyson et al. (2001). Consequently, the policy suggestions in these studies are not optimal.

Another shortcoming of above literature is that the researchers only considered energy input and ignored the undesirable output. Although energy input would affect undesirable output, if energy utilization efficiency can be improved, undesirable output would decline. Several scholars have measured the emission reduction performance of DMUs using methods such as the SBM model set up by Tone (2001) and the directional distance function (DDF) model set up by Chung et al. (1997). Many scholars have conducted detailed research based on these two models. For example, Sueyoshi and Goto (2011) measured the returns to scale of desirable output and damages to scale of undesirable output at the same time through the DEA model; Fukuyama and Weber (2009) developed a slack-based inefficiency measurement based on the DDF; Färe and Grosskopf (2010) proposed a generalized non-radial DDF; Barros et al. (2010) proposed a weighted Russell DDF.

Technological and environmental disparities exist among different areas in China, and the energy saving and emission reduction potential of every area varies as well. Thus, scholars have expressed great interest in identifying ways to evaluate the comprehensive environmental performance regarding energy saving and emission 
reduction of every area by using the DEA method(Shao, 2017). Thus, some scholars put forward that DMUs with similar environments should be classified into one group to carry out the environmental efficiency evaluation of every group respectively (Lin and Zhao, 2016). Shao (2017) and Tian et al. (2017) tried the above method as well. They named the production frontier that consisted of all DMUs as the meta-frontier and the production frontier composed of each group as the group-frontier. DMUs in each group only need to be optimal in their own groups. This method successfully solved the planning failure problem that resulted from the external environment.

The latest attempt was conducted by Feng and Wang (2017), which introduced the meta-frontier DEA into the evaluation of China' energy efficiency, and it decomposed energy efficiency and energy saving potential into three components-technology gap, management, and scale. However, although Feng and Wang considered the non-homogeneity of DMUs, they still did not include undesirable output into the analysis. We believe that if energy and pollution discharge are respectively taken as the input and undesirable output, it will be inevitably required for as few energy inputs and undesirable outputs as possible while as many outputs as possible. In this case, the radial evaluation method will not satisfy the requirements of evaluation. Furthermore, Feng and Wang (2017) took the ratio between the evaluation efficiency $\theta_{m}$ of DMUs on the meta-frontier and that on the group-frontier as the technology gap ratio. If the original model considered undesirable output, then $\theta_{m}$ and $\theta_{\mathrm{g}}$ would not be in the same direction but at an angle of $\beta$. The appearance of $\beta$ would have a considerable influence on the conclusions of the model.

In this study, we expand the energy efficiency model of Feng and Wang (2017) in an attempt to build an environmental efficiency model that considers regional non-homogeneity. Hereinafter, we will explain this viewpoint step by step and evaluate the environmental efficiency of each area in China.

\section{Methodologies}

In this section, we use the research method of Feng and Wang (2017) as reference to build the production possibility set of a lowcarbon economy $P P S_{t}$. Period $\mathrm{t}=1,2,3 \ldots \mathrm{T}$ and its $P P S_{t}$ meet the following assumptions:

Assumption 1. Envelopment assumption

$\left(Y_{j}^{t}, U_{j}^{t}, L_{j}^{t}, K_{j}^{t}, E_{j}^{t}\right) \in P P S_{t}, j=1,2, \ldots, n$

Assumption 2. Convexity assumption

If

$\left(Y_{j}^{t}, U_{j}^{t}, L_{j}^{t}, K_{j}^{t}, E_{j}^{t}\right) \in P P S_{t}$, and $\left(\widehat{Y}_{j}^{t}, \widehat{U}_{j}^{t}, \widehat{L}_{j}^{t}, \widehat{K}_{j}^{t}, \widehat{E}_{j}^{t}\right) \in P P S_{t}, j=1,2, \ldots, n$

then

$\alpha\left(Y_{j}^{t}, U_{j}^{t}, L_{j}^{t}, K_{j}^{t}, E_{j}^{t}\right)+(1-\alpha)\left(\widehat{Y}_{j}^{t}, \widehat{U}_{j}^{t}, \widehat{L}_{j}^{t}, \widehat{K}_{j}^{t}, \widehat{E}_{j}^{t}\right) \in P P S_{t}, \forall \alpha \in[0,1]$

Assumption 3. Cone assumption

If

$\left(Y_{j}^{t}, U_{j}^{t}, L_{j}^{t}, K_{j}^{t}, E_{j}^{t}\right) \in P P S_{t}, \lambda^{t} \geq 0$

then

$\lambda^{t}\left(Y_{j}^{t}, U_{j}^{t}, L_{j}^{t}, K_{j}^{t}, E_{j}^{t}\right) \in P P S_{t}$

According to Feng and Wang's model (2017), the improvement pathway of DMUs is input-oriented. It reaches the group-frontier first to realize the effectiveness of a group and then reaches the meta-frontier to realize the effectiveness of the whole. The gap between the group-frontier and meta-frontier is called the technological gap ratio. However, such an improvement mode has the following three aspects that do not meet the real social production status.

1) The original model did not consider the viscosity of input; that is, the ability of DMU shrinkage for each input is different. For example, because of the labor contract, large-scale job cutting cannot be carried out or the DMU cannot change fixed asset inputs, such as the equipment and workshop, in the short term. Practically, production factors have differences as regards property, use procedure, and position. Accordingly, their input viscosity is different, which was not considered in the original model.

2) By default, the original model considered that the output was invariant and was maintained at a fixed level no matter the first or second improvement. Moreover, the decision makers needed to increase output to gain more profits instead of reducing input. As the market price of one unit of goods is generally higher than the production cost, when there are increasing RTS, the cost saved by reducing one unit of input should be less than the profit increased by expanding one unit of production. Hence, maintaining the production level invariant does not conform to the manufacturers' principle of profit maximization.

3) The original model did not consider the strategic change in DMUs. During the two processes of being effective in a group and on the whole, DMUs always use the radial programming method. As it is radial improvement, all inputs can only be reduced based on the same proportions. This is in line with the thought that DMUs all use the same production strategy no matter the process of being effective on the group-frontier or the meta-frontier (as the direction of the two processes is the same). In fact, it also difficult for this point to meet with the true production status. When enterprises adopt a strategy and realize effectiveness on the group-frontier, their environment has changed already-not only the internal production structure, technology, and factor inputs, but also the external target manufacturers. Hence, as they are now at a higher position, enterprises are unlikely to adopt the original production strategy to improve efficiency. To continue optimizing production, manufacturers may adopt different production strategies.

\subsection{Comparison with Feng and Wang (2017)}

Feng and Wang (2017) only considered energy efficiency without the undesirable output to establish an environmental efficiency model that considers both energy and pollution. Thus, their research only used the radial programming model. Based on the original model, we further put forward Assumption 4 as follows.

Assumption 4. Disposable assumption

If

$\left(Y_{j}^{t}, U_{j}^{t}, L_{j}^{t}, K_{j}^{t}, E_{j}^{t}\right) \in P P S_{t}, j=1,2, \ldots, n$

and

$\widehat{Y}_{j}^{t} \leq Y_{j}^{t}, \widehat{U}_{j}^{t} \leq \theta U_{j}^{t}, \widehat{L}_{j}^{t} \geq L_{j}^{t}, \widehat{K}_{j}^{t} \geq K_{j}^{t}, \widehat{E}_{j}^{t} \geq E_{j}^{t}$

then

$\left(\widehat{Y}_{r}^{p}, \widehat{U}_{b}^{p}, \widehat{Z}_{f}^{(p, k)}, \widehat{X}_{i}^{p}, \widehat{Z}_{d}^{(p, k)}\right) \in P P S_{t}, 0 \leq \theta^{p} \leq 1$

According to Assumption 4, we added $\theta^{t}$ to express the weak disposability assumption of the undesirable output. This improved the default strong disposability assumption of undesirable output in the original model. In fact, the strong disposability assumption 


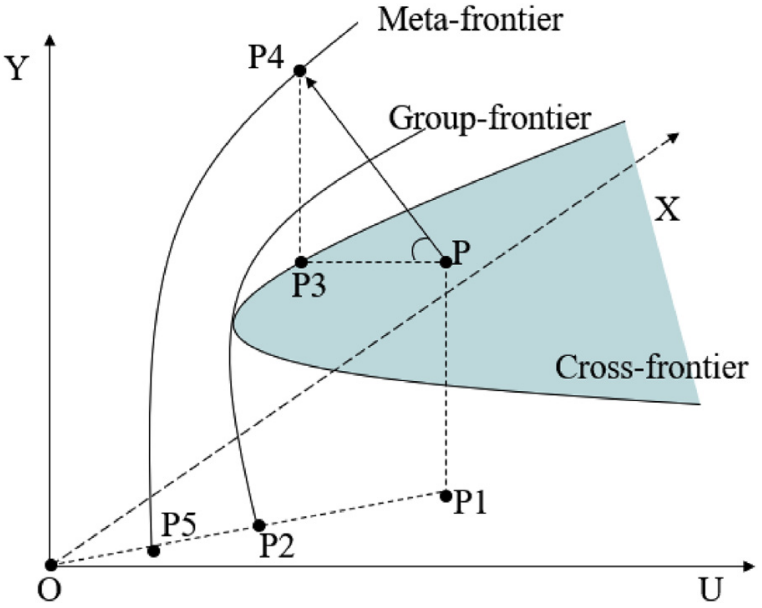

Fig. 2. Concept of the meta-frontier non-radial angle efficiency.

not only violated physical production but was also difficult to realize in the model's operation. That is because undesirable output cannot be illimitably reduced when energy input is fixed. Under the above axiomatic assumptions, $P P S_{t}$ is given as follows:

$$
\begin{gathered}
P P S_{t}=\left\{\left(Y_{j}^{t}, U_{j}^{t}, L_{j}^{t}, K_{j}^{t}, E_{j}^{t}\right) \mid \sum_{j=1}^{n} \lambda_{j}^{t} Y_{j}^{t} \geq Y^{t}, \theta^{t} \sum_{j=1}^{n} \lambda_{j}^{t} U_{j}^{t} \geq U^{t}, \sum_{j=1}^{n} \lambda_{j}^{t} L_{j}^{t} \geq L^{t},\right. \\
\left.\sum_{j=1}^{n} \lambda_{j}^{t} K_{j}^{t} \geq K^{t}, \sum_{j=1}^{n} \lambda_{j}^{t} E_{j}^{t} \geq E^{t}, \lambda_{j}^{p} \geq 0,0 \leq \theta^{p} \leq 1, j=1,2, \ldots, n\right\}
\end{gathered}
$$

The output set of period $t$ is

$P^{t}\left(L^{t}, K^{t}, E^{t}\right)=\left\{\left(Y^{t}, U^{t}\right) \mid\left(L^{t}, K^{t}, E^{t}\right)\right.$ can produce

$$
\left.\left(Y^{t}, U^{t}\right)\right\}, t=1.2, \ldots, T
$$

Formula (2) expresses the possible output combinations at period $t$ when the input was fixed. By summarizing the output combinations at different times, we can obtain the global output set $P^{G}=P^{1} \cup P^{2} \cup \ldots \cup P^{T}$.

If the undesirable output is to be considered, not only the constituents of the model but also the research thought will be changed greatly. Adoption of only radial programming will not be enough to realize the research objective. Moreover, the decision makers will have to reduce the input and undesirable output as well as increase output. Thus, to overcome the shortcomings of the radial model in meta-frontier application, we tried to use the non-radial method for measurement. Improvement can move toward the directions and sizes that are favorable for every input and output.

This study tries to set up a meta-frontier non-radial angle efficiency (MNAE) model that considers undesirable output as shown in Fig. 2. In the figure, $X$ refers to the input, $U$ refers to the undesirable output and $Y$ refers to the output. The meta-frontier and group-frontier are shown in the figure, and DMU $P$ is below the group-frontier. For simplicity, we call the envelop line that passes point $P$ and is parallel with plane $X U$ as the cross-frontier, and the projection of point $P$ on plane $X U$ is point $P_{1}$. According to the radial programming method of Feng and Wang (2017), in the first step, the input and undesirable output can be reduced to point $P_{2}$, while the output remains unchanged; in the second step, the input and undesirable output can be further reduced to point $P_{5}$, and $P_{2} P_{5} / P_{1} P_{5}$ is the technology gap ratio (TGR). This leads to the fact that DMUs $P$, $P_{2}$, and $P_{5}$ are in a same direction. Thus, both group-frontier and meta-frontier can be calculated as per the scalar quantity. Actually, such a definition is just the ratio of the norms of efficiency value vectors. That is why we redefine it as the pure technology gap ratio (PTGR).

As shown in Fig. 2, after introducing the undesirable output, DMU $P$ first moved to point $P_{3}$ in the direction of $P P_{3}$ and realized effectiveness in a group; output was increased while input was reduced in the same time; then, it moved to point $P_{4}$ in the direction of $P_{3} P_{4}$ and realized effectiveness on the whole; output was further increased while input was reduced in the same time. Though improvement at two times both realized an increase of output and reduction of input, due to different directions of $\mathrm{PP}_{3}$ and $P_{3} P_{4}$, there were differences in production strategy in the two programming as to DMUs. The slope of $\mathrm{PP}_{3}$ was bigger than that of $P_{3} P_{4}$, meaning that the priority of the first improvement was an increase of output, while that of the second improvement was a reduction of input. Because of limited resources, DMUs could only have one priority in a certain period, either to increase outputs or to reduce inputs. It is in line with the improvement strategy of DMUs. This method addressed the shortcomings of the radial model mainly in following aspects: 1) Each type of input did not have to change in the same proportion due to adoption of the SBM method; 2) the objective of increasing the output was realized; and 3) different production strategies were used by the DMUs for the two improvements.

If the programming of DMU $P$ follows the meta-frontier, its optimal programming objective will be $P_{4}$. Then, there will be an angle $\boldsymbol{\beta}$ between the vectors $P P_{3}$ and $P P_{4}$. According to the definition by Feng and Wang (2017), the technology gap ratio should be expressed as

$T G R=\frac{\left|\overrightarrow{P_{m}}\right|}{\left|\overrightarrow{P_{g}}\right|} \cos \beta=P T G R \times \cos \beta=P T G R \times A E$

Thus, the TGR can be decomposed to the product of PTGR and $\cos \beta \cdot \cos \beta$ is the angle efficiency $(A E)$, for which the range of values is $(0,1)$. When $A E=1$, the improvement pathways at the two times are the same. At this time, the MNAE model can be simplified to Feng and Wang's (2017) model. Thus, under the group-frontier, the MNAE model can be expressed as

$\min \rho_{g}\left(L_{0}, K_{0}, E_{0}, Y_{0}, U_{0} \mid C R S\right)$

$$
\left\{\begin{array}{l}
\sum_{j=1}^{N_{g}} \lambda_{j}^{t} L_{j}^{t}+S_{l}^{-}=L_{0}^{t}, \sum_{j=1}^{N_{g}} \lambda_{j}^{t} K_{j}^{t}+S_{k}^{-}=K_{0}^{t} \\
\sum_{j=1}^{N_{g}} \lambda_{j}^{t} Y_{j}^{t}-S_{y}^{+}=Y_{0}^{t}, \sum_{j=1}^{N_{g}} \lambda_{j}^{t} E_{j}^{t}+S_{e}^{-}=E_{0}^{t} \\
\theta^{t} \sum_{j=1}^{N_{g}} \lambda_{j}^{t} U_{j}^{t}+S_{u}^{-}=U_{0}^{t} \\
\lambda_{j}^{t} \geq 0, \theta^{t} \in(0,1], j=1,2, \ldots, N_{g}
\end{array}\right.
$$

Here, $\lambda_{j}^{t}$ refers to intensity vector used to build a fictitious DMU or projection-frontier. As formula (4) has a nonlinear formulation, 
we divide both sides of $\theta^{t} \sum_{j=1}^{N_{g}} \lambda_{j}^{t} U_{j}^{t}+S_{u}^{-}=U_{0}^{t}$ by $\theta^{t}$ and then set $\pi^{t}=1 / \theta^{t}$ and $M_{u}^{t}=S_{u}^{-} / \theta^{t}$. Accordingly, we get

$\min \rho_{g}\left(L_{0}, K_{0}, E_{0}, Y_{0}, U_{0} \mid C R S\right)$

$$
\left\{\begin{array}{l}
\sum_{j=1}^{N_{g}} \lambda_{j}^{t} L_{j}^{t}+S_{l}^{-}=L_{0}^{t}, \sum_{j=1}^{N_{g}} \lambda_{j}^{t} K_{j}^{t}+S_{k}^{-}=K_{0}^{t} \\
\sum_{j=1}^{N_{g}} \lambda_{j}^{t} Y_{j}^{t}-S_{y}^{+}=Y_{0}^{t}, \sum_{j=1}^{N_{g}} \lambda_{j}^{t} E_{j}^{t}+S_{e}^{-}=E_{0}^{t} \\
\sum_{j=1}^{N_{g}} \lambda_{j}^{t} U_{j}^{t}+M_{u}^{-}=\pi^{t} U_{0}^{t} \\
\lambda_{j}^{t} \geq 0, \pi^{t} \in(1,+\infty), j=1,2, \ldots, N_{g}
\end{array}\right.
$$

Similarly, under the meta-frontier, the MNAE model can be expressed as

$\min \rho_{m}\left(L_{0}, K_{0}, E_{0}, Y_{0}, U_{0} \mid C R S\right)$

$\left\{\begin{array}{l}\sum_{j=1}^{N} \lambda_{j}^{t} L_{j}^{t}+S_{l}^{-}=L_{0}^{t}, \sum_{j=1}^{N} \lambda_{j}^{t} K_{j}^{t}+S_{k}^{-}=K_{0}^{t} \\ \sum_{j=1}^{N} \lambda_{j}^{t} Y_{j}^{t}-S_{y}^{+}=Y_{0}^{t}, \sum_{j=1}^{N} \lambda_{j}^{t} E_{j}^{t}+S_{e}^{-}=E_{0}^{t} \\ \sum_{j=1}^{N} \lambda_{j}^{t} U_{j}^{t}+M_{u}^{-}=\pi^{t} U_{0}^{t} \\ \lambda_{j}^{t} \geq 0, \pi^{t} \in(1,+\infty), j=1,2, \ldots, N\end{array}\right.$

If we add $\sum \lambda_{j}^{t}=1$ in its constraint conditions, it indicates that there are variable returns to scale (VRS), from which we can get efficiency values under VRS as $\rho_{g}(V R S)$ and $\rho_{m}(V R S)$, respectively. We define slack variables gained by the group-frontier as $\left(S_{l}^{g-}, S_{k}^{g-}, S_{e}^{g-}, S_{y}^{g-}, S_{u}^{g-}\right)$ and those by the meta-frontier as $\left(S_{l}^{m-}, S_{k}^{m-}, S_{e}^{m-}, S_{y}^{m-}, S_{u}^{m-}\right)$. Then, we get

$\overrightarrow{P P}_{3}=\left(S_{l}^{g-}, S_{k}^{g-}, S_{e}^{g-}, S_{y}^{g-}, S_{u}^{g-}\right)$,

$\overrightarrow{P P}_{4}=\left(S_{l}^{m-}, S_{k}^{m-}, S_{e}^{m-}, S_{y}^{m-}, S_{u}^{m-}\right)$,

And

$$
\begin{aligned}
A E & =\cos \beta=\frac{\overrightarrow{P P}_{3} \cdot \overrightarrow{P P}_{4}}{\left|\overrightarrow{P P}_{3}\right| \times\left|\overrightarrow{P P}_{4}\right|} \\
& =\frac{S_{l}^{g-} S_{l}^{m-}+S_{k}^{g-} S_{k}^{m-}+S_{e}^{g-} S_{e}^{m-}+S_{y}^{g-} S_{y}^{m-}+S_{u}^{g-} S_{u}^{m-}}{\sqrt{\sum_{i=m, g}\left(S_{l}^{i-}\right)^{2}+\left(S_{k}^{i-}\right)^{2}+\left(S_{e}^{i-}\right)^{2}+\left(S_{y}^{i-}\right)^{2}+\left(S_{u}^{i-}\right)^{2}}}
\end{aligned}
$$

Objective functions $\rho_{g}$ and $\rho_{m}$ in formulae (4) to (6), respectively, refer to be-solved objective functions under the group-frontier and meta-frontier. To prevent the shadow price of the undesirable output being negative, we adopt an input-oriented slack-based measure for modification. Expression of objective function is as follows:

In the input orientation:

$\rho=1-\left(\frac{S_{l 0}^{t-}}{L_{0}^{t}}+\frac{S_{k 0}^{t-}}{K_{0}^{t}}+\frac{S_{e 0}^{t-}}{E_{0}^{t}}\right)$

\subsection{Global Malmquist index with non-radical decomposition}

Using Oh (2010) as reference, the Global Malmquist (GM) index for measuring efficiency changes from period $t$ to period $t+1$ and can be defined as follows:

$G M^{t, t+1}=\frac{\rho_{m}^{G}\left(L_{0}^{t+1}, K_{0}^{t+1}, E_{0}^{t+1}, Y_{0}^{t+1}, U_{0}^{t+1} \mid C R S\right)}{\rho_{m}^{G}\left(L_{0}^{t}, K_{0}^{t}, E_{0}^{t}, Y_{0}^{t}, U_{0}^{t} \mid C R S\right)}$

In the total factor low-carbon economy efficiency value $\rho_{m}^{G}$, $G$ refers to being under the global period's benchmark technology; that is, when calculating the relative efficiency using the DEA method, DMUs at all periods are included in the range of evaluation. When $G M^{t, t+1}$ is respectively higher, equal to, or lower than 1 , it is deemed that efficiency at period $t+1$ is higher, equal to, or lower than that at period t. According to Pastor and Lovell (2005), the GM index can be decomposed into $G T C H^{t, t+1}$ and $G E C H^{t, t+1}$ :

$G M^{t, t+1}=G T C H^{t, t+1} \times G E C H^{t, t+1}$,

$G T C H^{t, t+1}=\frac{\rho_{m}^{G}\left(L_{0}^{t+1}, K_{0}^{t+1}, E_{0}^{t+1}, Y_{0}^{t+1}, U_{0}^{t+1} \mid C R S\right)}{\rho_{m}^{t+1}\left(L_{0}^{t+1}, K_{0}^{t+1}, E_{0}^{t+1}, Y_{0}^{t+1}, U_{0}^{t+1} \mid C R S\right)}$

$/ \frac{\rho_{m}^{G}\left(L_{0}^{t}, K_{0}^{t}, E_{0}^{t}, Y_{0}^{t}, U_{0}^{t} \mid C R S\right)}{\rho_{m}^{t}\left(L_{0}^{t}, K_{0}^{t}, E_{0}^{t}, Y_{0}^{t}, U_{0}^{t} \mid C R S\right)}$

$G M^{t, t+1}=\frac{\rho_{m}^{G}\left(L_{0}^{t+1}, K_{0}^{t+1}, E_{0}^{t+1}, Y_{0}^{t+1}, U_{0}^{t+1} \mid C R S\right)}{\rho_{m}^{G}\left(L_{0}^{t}, K_{0}^{t}, E_{0}^{t}, Y_{0}^{t}, U_{0}^{t} \mid C R S\right)}$

$\mathrm{t}$ and $\mathrm{t}+1$ in the total factor low-carbon economy efficiency values $\rho_{m}^{t}$ and $\rho_{m}^{t+1}$ respectively indicate that periods $t$ and $t+1$ are taken as benchmarks. That is, when calculating the relative efficiency using the DEA method, DMUs at periods $t$ and $t+1$ are included in the range of evaluation. $G E C H^{t, t+1}$ indicates a change in technology, which is used to measure time-dependent variations of the ratio between the technology level at all times and at period t. GECH ${ }^{t, t+1}$ is used to calculate time-dependent variations of the ratio between total factor productivity in period $\mathrm{t}+1$ and in period $\mathrm{t}$ when periods $\mathrm{t}+1$ and $\mathrm{t}$ are taken as benchmarks. When $\mathrm{GTCH}^{t, t+1}$ and $G E C H^{t, t+1}$ are respectively higher, equal to, or lower than 1 , technology and efficiency in period $t+1$ are respectively higher, equal to, or lower than technology and efficiency in period t. Wang et al. (2013) further decomposed $G E C H^{t, t+1}$ into change in technology gap ratio between the group-frontier and meta-frontier (TGCH), change in scale efficiency under the group-frontier $(S E C H)$, and change in management efficiency under the group-frontier $(M E C H)$. When $T G C H, S E C H$, and $M E C H$ are respectively higher, equal to, or lower than 1 , the technology gap, scale efficiency, and management efficiency at period $t+1$ are respectively higher, equal to, or lower than those in period t. Under the condition of non-radial decomposition, we can decompose GM index into:

$G M^{t, t+1}=G T C H^{t, t+1} \times A E C H^{t, t+1} \times P T G C H^{t, t+1} \times S E C H^{t, t+1}$

$\times M E C H^{t, t+1}$

Among which

$A E C H^{t, t+1}=A E^{t+1} / A E^{t}$

$\mathrm{PTGCH}^{t, t+1}=\frac{\rho_{m}^{t+1}\left(L_{0}^{t+1}, K_{0}^{t+1}, E_{0}^{t+1}, Y_{0}^{t+1}, U_{0}^{t+1} \mid C R S\right)}{\rho_{\mathrm{g}}^{t+1}\left(L_{0}^{t+1}, K_{0}^{t+1}, E_{0}^{t+1}, Y_{0}^{t+1}, U_{0}^{t+1} \mid C R S\right)}$

$/ \frac{\rho_{m}^{t}\left(L_{0}^{t}, K_{0}^{t}, E_{0}^{t}, Y_{0}^{t}, U_{0}^{t} \mid C R S\right)}{\rho_{g}^{t}\left(L_{0}^{t}, K_{0}^{t}, E_{0}^{t}, Y_{0}^{t}, U_{0}^{t} \mid C R S\right)}$ 
$S E C H^{t, t+1}=\frac{\rho_{g}^{t+1}\left(L_{0}^{t+1}, K_{0}^{t+1}, E_{0}^{t+1}, Y_{0}^{t+1}, U_{0}^{t+1} \mid C R S\right)}{\rho_{g}^{t+1}\left(L_{0}^{t+1}, K_{0}^{t+1}, E_{0}^{t+1}, Y_{0}^{t+1}, U_{0}^{t+1} \mid C R S\right)}$

$$
/ \frac{\rho_{g}^{t}\left(L_{0}^{t}, K_{0}^{t}, E_{0}^{t}, Y_{0}^{t}, U_{0}^{t} \mid C R S\right)}{\rho_{g}^{t}\left(L_{0}^{t}, K_{0}^{t}, E_{0}^{t}, Y_{0}^{t}, U_{0}^{t} \mid C R S\right)}
$$

$M E C H^{t, t+1}=\frac{\rho_{g}^{t+1}\left(L_{0}^{t+1}, K_{0}^{t+1}, E_{0}^{t+1}, Y_{0}^{t+1}, U_{0}^{t+1} \mid V R S\right)}{\rho_{g}^{t}\left(L_{0}^{t}, K_{0}^{t}, E_{0}^{t}, Y_{0}^{t}, U_{0}^{t} \mid V R S\right)}$

\section{Data and descriptive statistics}

Tibet was not included in our analysis due to lack of data. Data for the other 30 provinces of China from 2005 to 2015 were selected as the research sample in which the $11^{\text {th }}$ and $12^{\text {th }}$ Five-year Plans were covered. The computing methods of the model's input and output indexes are as below:

1) Capital stock (K): The perpetual inventory method is used to estimate the capital stock as follows:

$K_{t}=K_{t-1}(1-\delta)+I_{t} / P_{t}$

where $\mathrm{t}$ refers to time; $K_{t}$ refers to the capital stock in year $\mathrm{t} ; \delta$ refers to the depreciation rate and equals $9.6 \%$; $I$ refers to investment in year $t$; and $P$ refers to the price index. Moreover, 2003 is taken as the base year. As the State Statistics Bureau no longer announces the aggregate data on capital and investment since 1993, we replace $I$ with the total investment in fixed assets and $P$ with the price index of investment in fixed assets. The relevant data are aggregated from each year's China Statistical Yearbook from 2005 to 2016.

1) Labor input (L) and output (Y): The year-end number of employees and industrial gross output are respectively used to represent labor input and output. Data are aggregated from each year's China City Statistical Yearbook.

2) Consumption of standard coal (SC): The products of consumption and standard coal coefficient of nine energy sources are summed up to represent SC. The nine energy sources include coal, coke, crude oil, petroleum, kerosene, diesel, fuel oil, natural gas, and electric power. Standard coal consumption is calculated as follows:

$S C=\sum_{i=1}^{9}\left(a \times E_{i}\right)$

Where $a$ stands for the standard coal coefficient, and $E$ stands for energy consumption. Data are aggregated from each year's China Energy Statistical Yearbook.

1) Undesirable output index (UO). Fumes emission and sulfur dioxide $\left(\mathrm{SO}_{2}\right)$ emission are used to represent the undesirable output. The data are aggregated from each year's China Environment Statistical Yearbook and the website of the State Statistical Bureau.

\section{Empirical analysis results and discussion}

Report of the $19^{\text {th }}$ National Congress of the Communist Party of China pointed out that the unbalanced economic development in China has become the principal contradiction in Chinese society. The eastern region in China has developed very fast, while the central and western regions are lagging behind. Moreover, the economic gap among these regions is increasing gradually. Many scholars have already carried out environmental efficiency
Table 1

Summary statistics of inputs and outputs.

\begin{tabular}{lllllll}
\hline Index & Unit & Obs. & Min & Max & Mean & Std. Dev. \\
\hline K & trillion RMB & 360 & 14.310 & 235.616 & 96.517 & 73.116 \\
L & million person & 360 & 108.373 & 185.142 & 136.714 & 30.354 \\
SC & billion tons & 360 & 2.233 & 5.932 & 4.134 & 1.294 \\
Y & trillion RMB & 360 & 16.770 & 72.174 & 42.903 & 19.490 \\
UO & billion tons & 360 & 2.377 & 6.940 & 4.952 & 1.721
\end{tabular}

analyses of 30 provinces in these three broad regions (Watanabe and Tanaka, 2007), but most provinces in the central and western regions have failed to improve as planned due to non-homogeneity among DMUs. Therefore, this study uses the meta-frontier method for analysis. This section presents the MNAE efficiency values of China's 30 provinces and then decomposes them. Next, it conducts regression analysis to identify each area's key index that stimulates its development as well as identify its energy saving and emission reduction potential. All estimations in this study are based on provincial panel data (Table 1 ).

\subsection{Analysis of MNAE changes}

We obtain the MNAE values of China's 30 provinces according to formulae (5) and (6) and divide them as per the eastern, central, and western regions to determine the average MNAE value of each region. For easy understanding, we illustrate the MNAE trends as shown as Fig. 3.

We use the bold line to represent the meta-frontier efficiency values and fine lines to represent group-frontier efficiency values. The eastern, central, and western regions are expressed by blue, yellow, and red colors, respectively. The greater is the gap between the meta-frontier and group-frontier is, the greater is the gap between the efficiency level of one region and the overall efficiency level. Fig. 3 shows that eastern region's the group-frontier efficiency value is in accordance with its meta-frontier efficiency value; however, there is a small distance between these values for the central region but a greater distance for the western region. This indicates that efficiency in the western region is very low, and great effort should be made to change the existing conditions.

We individually listed the pure technological gap ratios of 11 provinces in the western region. Table 2 shows that the decline in Guizhou, Shaanxi, Yunnan, and Qinghai has been significant since 2010, indicating that the development of economy and technology in these provinces has gradually fallen behind other provinces. Besides, underdeveloped areas suffered more growth resistance during the global financial crisis of 2007, while the developed eastern region, having great potential for economic growth, was prioritized by every economic entity for investment after the global economy recovery since 2010 . This further aggravated the decline of economic efficiency in the western region

\subsection{Decomposition of MNAE}

According to formula (15), we calculate the decomposed MNAE values of the eastern, central, and western regions. Please refer to Table 4 for details.

In the eastern region, changes in $G T C H, P T G C H, S H C H$, and $M E C H$ were not significant, while change in only $A E C H$ from 2007 to 2008 was significant. AECH was 0.5 in 2007 and rose to 1.9 in 2008, indicating that production decisions had changed greatly in the eastern region from 2007 to 2008 . The $A E$ index put forward in this study is used to measure the angle between being optimal in the groupfrontier and directly being optimal in the meta-frontier. If the angle was large, there would be great differences in the decisions of DMUs when pursuing the short-term or long-term optimum. Such differ- 


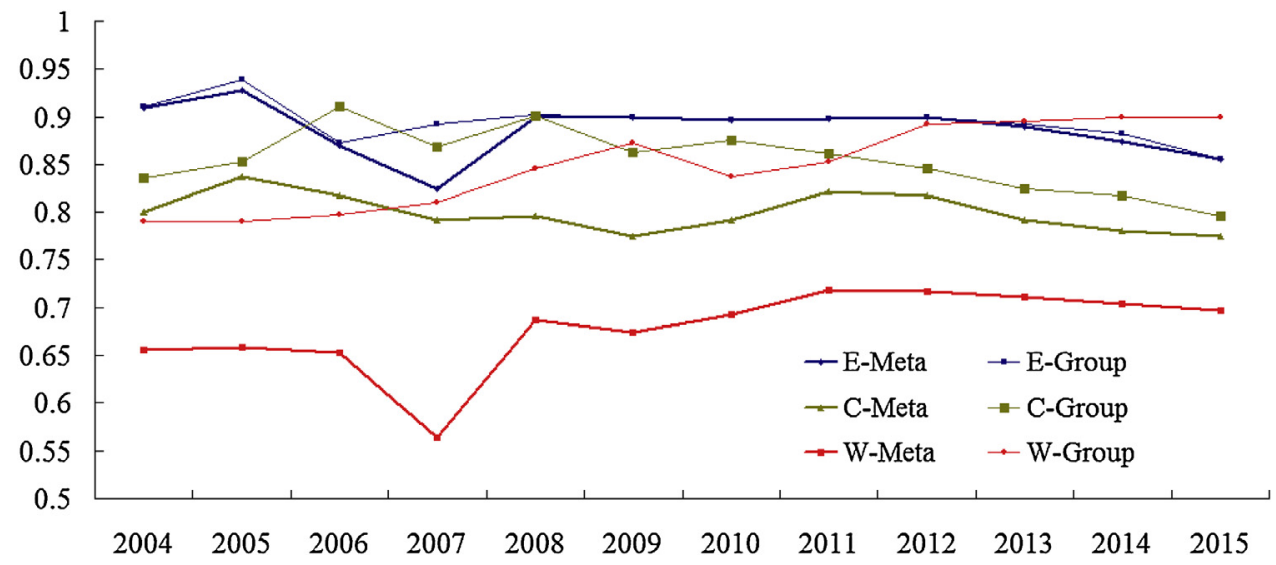

Fig. 3. Annual changes in MNAE efficiency values in China between 2004 and 2015.

Note: E represents eastern China, $C$ represents central China, and W represents western China.

Table 2

Pure technological gap ratio in western China.

\begin{tabular}{|c|c|c|c|c|c|c|c|c|c|c|c|}
\hline Year & Sichuan & Chongqing & Guizhou & Yunnan & Shaanxi & Gansu & Qinghai & Ningxia & Xinjiang & Guangxi & Inner Mongolia \\
\hline 2004 & 0.819 & 0.607 & 0.779 & 1.000 & 0.736 & 0.782 & 0.977 & 0.726 & 1.000 & 0.786 & 0.870 \\
\hline 2005 & 0.835 & 0.639 & 0.845 & 0.806 & 0.793 & 0.826 & 0.998 & 0.840 & 1.000 & 0.761 & 0.897 \\
\hline 2006 & 0.822 & 0.594 & 0.830 & 0.741 & 0.786 & 0.824 & 1.000 & 0.861 & 1.000 & 0.759 & 0.929 \\
\hline 2007 & 0.696 & 0.491 & 0.729 & 0.715 & 0.729 & 0.779 & 0.720 & 0.793 & 0.665 & 0.731 & 0.720 \\
\hline 2008 & 0.724 & 0.665 & 0.767 & 0.814 & 0.703 & 0.804 & 0.993 & 0.865 & 1.000 & 0.747 & 0.945 \\
\hline 2009 & 0.715 & 0.676 & 0.636 & 0.792 & 0.714 & 0.756 & 0.944 & 0.833 & 1.000 & 0.728 & 0.793 \\
\hline 2010 & 0.733 & 0.708 & 0.775 & 0.853 & 0.722 & 0.824 & 1.000 & 0.915 & 1.000 & 0.725 & 0.964 \\
\hline 2011 & 0.776 & 0.785 & 0.806 & 0.822 & 0.768 & 0.809 & 0.978 & 0.918 & 1.000 & 0.767 & 0.898 \\
\hline 2012 & 0.818 & 0.645 & 0.620 & 0.792 & 0.799 & 0.776 & 0.930 & 0.867 & 1.000 & 0.783 & 0.870 \\
\hline 2013 & 0.708 & 0.634 & 0.668 & 0.766 & 0.744 & 0.771 & 0.912 & 0.895 & 1.000 & 0.760 & 0.950 \\
\hline 2014 & 0.753 & 0.646 & 0.667 & 0.727 & 0.722 & 0.763 & 0.918 & 0.773 & 1.000 & 0.743 & 0.930 \\
\hline 2015 & 0.694 & 0.666 & 0.694 & 0.726 & 0.699 & 0.752 & 0.860 & 0.762 & 1.000 & 0.740 & 0.929 \\
\hline
\end{tabular}

ences in decisions usually lead to waste in the production process. Generally, due to influence of the leader, each production decision of each DMU does not change sharply in a certain period. If so, there must be changes of surrounding environment. It is safe to say that the $A E$ index reflects the environmental change that DMUs face.

The eastern region's economy is the most developed in China. The economy, technology, and culture of this region are under the influence of foreign direct investment (FDI). Import and export are moving upward day by day, which makes this region very sensitive to export and investment. The global economic crisis during 2007 and 2008 resulted caused a global economic downturn and reduction of orders, compelling the eastern region to change trade patterns. The product processing and manufacturing industries, which previously catered to export, now turned toward the domestic market. Thus, the economic crisis affected the $A E$ index of the eastern region and resulted in great fluctuations. However, from 2009 , the eastern region gradually adapted to the unfavorable influences of the economic crisis and adopted a post-crisis economic growth mode. Therefore, its $A E$ index eventually gained stability.

Effects of the economic crisis in 2008 on the $A E$ index of the western region were not as significant as those in 2010. This may be because this region was not sensitive to global economic fluctuations and did not communicate with external regions frequently. Besides, decline of sales of bulk goods was also an important reason for the change in production decisions in the western region. Based on analysis of these three regions, fluctuation of the $A E$ index of the western region was the sharpest and its production decisions changed frequently. This indicates that the western region had not found the way that was suitable for its development and could not sustain its comparative advantages and core competitiveness in a turbulent environment.
The $A E$ index of the central region was smooth from beginning to end. This indicated that while the production decisions of this region were consistent all the time, communications between this region and the world were rare. Thus, the central region needs to open up trade and investment to guarantee fast development of the economy and technology.

\subsection{Regression and analysis of $\mathrm{AE}$}

The external environment impacts every province through interference of uncontrollable factors such as natural disaster, war, disease, and religion. To measure the external influences on each province, we collected the data on total import and export volumes as well as the FDI index for each province from 2005 to 2015. Based on the individual $A E$ index of each province, the $A E$ values of Beijing, Shanghai, Guangdong, and Shenzhen were always 1, indicating that these cities were on the production frontier all along. Upon eliminating these cities for an ordinary least squares regression analysis, we found that the import and export volumes and FDI indexes of eight provinces had significant influences on their $A E$ index. According to Table 3, influence of the FDI index was significant for Fujian and Shandong, and it was positive for Fujian. This indicated that the previous production decision of Fujian was enhanced along with input of FDI. Thus, FDI could stimulate the development of the economy and technology in Fujian. The regression coefficient of FDI for Shandong was negative, meaning that there was a large deviation in the production decision of Shandong with the input of FDI. This also explained that FDI interfered with the normal development of the economy of Shandong, even though it had issued many preferential policies over the years to attract foreign business and investment. Some other provinces in China also faced interference through the input of FDI, including Henan, 
Table 3

Annual changes in MNAE and its decomposition in the eastern, central, and western region between 2005 and 2015 .

\begin{tabular}{|c|c|c|c|c|c|c|}
\hline \multicolumn{7}{|c|}{ Eastern } \\
\hline Year & GM & GTCH & $\mathrm{AHCH}$ & PTGCH & $\mathrm{SHCH}$ & $\mathrm{MECH}$ \\
\hline 2005 & 0.963 & 0.918 & 1.029 & 0.988 & 1.025 & 1.006 \\
\hline 2006 & 0.910 & 1.013 & 0.957 & 1.009 & 0.944 & 0.984 \\
\hline 2007 & 0.511 & 1.075 & 0.502 & 0.926 & 1.048 & 0.975 \\
\hline 2008 & 1.963 & 0.944 & 1.904 & 1.081 & 1.004 & 1.006 \\
\hline 2009 & 1.009 & 0.926 & 1.090 & 1.003 & 0.997 & 1.000 \\
\hline 2010 & 1.031 & 1.027 & 1.007 & 1.000 & 0.999 & 0.998 \\
\hline 2011 & 1.040 & 1.034 & 1.003 & 1.000 & 0.993 & 1.010 \\
\hline 2012 & 0.940 & 0.997 & 0.942 & 1.000 & 1.001 & 1.001 \\
\hline 2013 & 0.964 & 0.994 & 0.982 & 0.996 & 0.973 & 1.019 \\
\hline 2014 & 1.018 & 1.019 & 1.016 & 0.994 & 0.996 & 0.994 \\
\hline 2015 & 1.003 & 1.016 & 1.008 & 1.010 & 0.970 & 1.000 \\
\hline \multicolumn{7}{|c|}{ Central } \\
\hline 2005 & 1.101 & 0.917 & 1.146 & 1.027 & 0.997 & 1.023 \\
\hline 2006 & 0.957 & 0.953 & 1.029 & 0.914 & 1.073 & 0.995 \\
\hline 2007 & 0.959 & 1.073 & 0.922 & 1.016 & 0.978 & 0.976 \\
\hline 2008 & 0.863 & 0.979 & 0.877 & 0.970 & 0.982 & 1.056 \\
\hline 2009 & 1.031 & 0.937 & 1.130 & 1.016 & 0.966 & 0.992 \\
\hline 2010 & 1.089 & 1.011 & 1.056 & 1.007 & 1.011 & 1.003 \\
\hline 2011 & 1.131 & 1.037 & 1.051 & 1.054 & 0.999 & 0.985 \\
\hline 2012 & 1.011 & 1.015 & 1.001 & 1.015 & 0.991 & 0.991 \\
\hline 2013 & 0.913 & 1.003 & 0.939 & 0.995 & 0.982 & 0.993 \\
\hline 2014 & 1.051 & 1.026 & 1.039 & 0.994 & 1.022 & 0.971 \\
\hline 2015 & 1.047 & 1.013 & 1.042 & 1.018 & 0.996 & 0.979 \\
\hline \multicolumn{7}{|c|}{ Western } \\
\hline 2005 & 0.733 & 0.912 & 0.800 & 1.004 & 1.000 & 1.000 \\
\hline 2006 & 0.919 & 0.946 & 0.978 & 0.985 & 0.999 & 1.009 \\
\hline 2007 & 1.179 & 1.133 & 1.205 & 0.849 & 1.006 & 1.011 \\
\hline 2008 & 0.504 & 0.847 & 0.489 & 1.166 & 1.025 & 1.018 \\
\hline 2009 & 0.705 & 0.922 & 0.778 & 0.952 & 1.012 & 1.019 \\
\hline 2010 & 2.372 & 0.994 & 2.323 & 1.070 & 0.968 & 0.991 \\
\hline 2011 & 0.902 & 1.002 & 0.868 & 1.018 & 1.010 & 1.008 \\
\hline 2012 & 0.943 & 0.976 & 0.967 & 0.954 & 1.034 & 1.013 \\
\hline 2013 & 0.720 & 0.963 & 0.755 & 0.988 & 0.985 & 1.018 \\
\hline 2014 & 1.068 & 1.001 & 1.078 & 0.986 & 1.014 & 0.990 \\
\hline 2015 & 0.907 & 0.995 & 0.920 & 0.988 & 1.008 & 0.994 \\
\hline
\end{tabular}

Table 4

Results of the regression.

\begin{tabular}{llllll}
\hline Region & Trade & FDI & Region & Trade & FDI \\
\hline \multirow{2}{*}{ Fujian } & 9.08 & $5.08^{* * *}$ & Jiangxi & $-1.63^{*}$ & $1.03^{*}$ \\
& $(0.16)$ & $(2.62)$ & & $(-1.85)$ & $(1.79)$ \\
\multirow{2}{*}{ Henan } & $1.36^{*}$ & $-5.47^{*}$ & Shandong & 4.80 & $-2.24^{*}$ \\
\multirow{2}{*}{ Jiangsu } & $(0.14)$ & $(-1.52)$ & & $(0.91)$ & $(-1.42)$ \\
& $-3.78^{*}$ & $6.11^{*}$ & Liaoning & $1.08^{*}$ & $-3.11^{*}$ \\
\multirow{2}{*}{ Chongqing } & $(-1.62)$ & $(1.49)$ & & $(1.36)$ & $(-1.38)$ \\
& $9.28^{* *}$ & -4.52 & Hunan & $1.57^{* *}$ & $-4.69^{* *}$ \\
& $(1.95)$ & $(-0.51)$ & & $(1.73)$ & $(-1.68)$ \\
\hline
\end{tabular}

Note: ${ }^{*}, * *$, and ${ }^{* * *}$ refer to the estimated values of parameters being significant at the $15 \%, 10 \%$, and $5 \%$ levels, respectively; values in parentheses are $T$ values of the estimated values of every parameter.

Chongqing, Liaoning, and Hunan. Thus, we should consider FDI to China in recent years more rationally to prevent resource waste and management errors resulting from the blind introduction of FDI.

Influences of import and export trades on provinces such as Hunan, Chongqing, Liaoning, and Henan were positive, meaning that import and export trades could stimulate stable improvement of the economy and maintain robustness of the government and enterprise decisions in these areas. These areas should develop import and export trades with great force to improve their economic abilities. However, for Jiangsu and Jiangxi, influences of import and export trades were negative, indicating that import and export trades were not suitable for local economic growth. Thus, these provinces should made efforts to attract FDI and maintain the robustness of policies to avoid resource waste.

\section{Conclusions}

Energy saving and emission reduction are inevitably required for improvement of environmental efficiency (Song and Wang, 2017). However, emission reduction will also lead to output decline, thus developing a contradiction between economic growth and environmental protection.

In this study, we modified the model of Feng and Wang (2017) and set up the MNAE model, which effectively transformed the radial evaluation method into the non-radial method and improved the conclusions of Feng and Wang (2017). In the MNAE model, we built a new $A E$ index to measure environmental changes that each DMU faces. Thus, in the empirical analysis, the $A E$ index was used to measure environmental changes in the eastern and western regions during 2005 and 2015 and to analyze trade and investment in each province. We obtained the following conclusions.

First, the pure technological gap between the eastern, central, and western regions was still significant during the study period. Therefore, to improve the economic levels in the central and western regions, we need to stimulate greater technology flow. However, according to the empirical results, technological change in the central region was not as significant as that in the eastern region. Besides, $S H C H$ and $M E C H$ of the central region became stable since 2011. Because of the disappearance of demographic dividend, the Chinese economy's growth rate declined moderately, and the period of the "New Normal" began from 2011. In China, economic growth in this period can only be achieved by stimulating economic transformation and technological innovation. From the estimation of $\mathrm{SHCH}$ and $\mathrm{MECH}$, the decline in economic growth rate made enterprises or management staff incapable of adapting to such changes. From 2011 to 2015, enterprise scale and management pattern did not change significantly, and $\mathrm{SHCH}$ and $\mathrm{MECH}$ were in a "dead state" no matter the region-the developed eastern region or underdeveloped central and western regions.

Secondly, during the sample period, each province made some changes on the trend of economic growth. Judging from the $A E$ index, influences of economic crisis on the eastern, central, and western regions of China varied. The eastern region was sensitive to the fluctuation of the global economy and was able to quickly adjust production decisions accordingly. The western region lagged relatively behind, and the production decisions of provinces in this region were only affected one year after the economic crisis. From the estimation values of $A E$, the $A E$ fluctuation range of the western region was larger than that of the eastern region, indicating that the $A E$ effect in the western region was much stronger than that in the eastern region, although responses of the former to global economic fluctuation lagged behind. This cause waste of many resources and lag in management. There was no $A E$ overshoot effect in the central region, which implied that this region rarely had communication with the global economy. Hence, this region should enhance cooperation and communication with the outside world under the push of China's "Rise of Central China" strategy.

Third, trade and FDI had significant influences on government decisions, especially in three provinces (Jiangsu, Shandong, and Fujian) of the eastern region, three provinces (Jiangxi, Hunan, and Henan) of the central region, and one province (Chongqing) of the Western region. Trade interfered significantly with government decisions in Jiangsu and Jiangxi, while FDI interfered negatively on government decisions in Henan, Chongqing, Shandong, Liaoning, and Hunan. Although the government eagerly advocates attracting foreign business and investment, not all FDI is "introduced" in good will nor is able to stimulate local economic development. Many FDIs are looking for resources or pollution transfer. In the short term, these FDIs may bring great returns to the local area, but they will be unfavorable to that area's sustainable development in long term. When comparing the short-term and long-term objec- 
tive, that is, comparing Group-frontier optimum and Meta-frontier optimum, contradiction between them is noticed. Moreover, the pursuit of short-term and long-term optimums also causes waste of resources and faults in management.

Finally, based on the MNAE model and $A E$ index discussed in this study, we consider that different regions in China should focus on their own advantages and develop local industries with core competitiveness to remain free from influences of the external environment and short-term benefits. An overall long-term development objective should be considered to guarantee long-term coordinated development between the economy and environment.

\section{Acknowledgements}

This work was supported by National Natural Science Foundation of China (Grant Nos. 71471001 and 71601170), the Program for Projects in Philosophy and Social Science Research of the Ministry of Education of China (Grant Nos. 14JZD031 and 16YJC630123), and New Century Excellent Talents in University (Grant No. NCET-120595).

\section{References}

BP, 2011. Statistical Review of World Energy. http://www.bp.com/statisticalreview/

Barros, C.P., Managi, S., Yoshida, Y., 2010. Productivity growth and biased technological change in Japanese airports. Transp. Policy (Oxf.) 17 (4), 259-265.

Chung, Y.H., Färe, R., Grosskopf, S., 1997. Productivity and undesirable outputs: a directional distance function approach. J. Environ. Manage. 51 (3), 229-240.

Cook, W.D., Seiford, L.M., 2009. Data envelopment analysis (DEA)-thirty years on. Eur. J. Oper. Res. 192 (1), 1-17, http://dx.doi.org/10.1016/j.ejor.2008.01.032/.

Dyson, R.G., Allen, R., Camanho, A.S., Podinovski, V.V., Sarrico, C.S., Shale, E.A., 2001. Pitfalls and protocols in DEA. Eur. J. Oper. Res. 132 (2), 245-259, http://dx.doi. org/10.1016/S0377-2217(00)00149-1/.

Färe, R., Grosskopf, S., 2010. Directional distance functions and slacks-based measures of efficiency. Eur. J. Oper. Res. 200 (1), 320-322, http://dx.doi.org/10.1016/ j.ejor.2009.01.031/.

Feng, C., Wang, M., 2017. Analysis of energy efficiency and energy savings potential in China's provincial industrial sectors. J. Clean. Prod. 164, 1531-1541, http:// dx.doi.org/10.1016/j.jclepro.2017.07.081/.

Fukuyama, H., Weber, W.L., 2009. A directional slacks-based measure of technical inefficiency. Socioecon. Plan. Sci. 43 (4), 274-287, http://dx.doi.org/10.1016/j. seps.2008.12.001/.

Glucker, A.N., Driessen, P.P., Kolhoff, A., Runhaar, H.A., 2013. Public participation in environmental impact assessment: why, who and how? Environ. Impact Assess. Rev. 43, 104-111, http://dx.doi.org/10.1016/j.eiar.2013.06.003/.

Guo, L.L., Qu, Y., Tseng, M.L., 2017. The interaction effects of environmental regulation and technological innovation on regional green growth performance. J. Clean. Prod. 162, 894-902, http://dx.doi.org/10.1016/j.jclepro.2017.05.210/.

Haas, D.A., 1998. Evaluating the Efficiency of Municipal Reverse Logistics Channels: an Application of Data Envelopment Analysis. Temple University, Philadelphia, US.
Honma, S., Hu, J.L., 2008. Total-factor energy efficiency of regions in Japan. Energy Policy 36 (2), 821-833, http://dx.doi.org/10.1016/j.enpol.2007.10.026/.

Li, K., Lin, B.Q., 2015. Metafroniter energy efficiency with $\mathrm{CO}_{2}$ emissions and its convergence analysis for China. Energy Econ. 48, 230-241, http://dx.doi.org/10. 1016/j.eneco.2015.01.006/.

Lin, B.Q., Yang, L.S., 2014. Efficiency effect of changing investment structure on China's power industry. Renew. Sustain. Energy Rev. 39, 403-411, http://dx. doi.org/10.1016/j.rser.2014.07.018/.

Lin, B.Q., Zheng, Q.Y., 2017. Energy efficiency evolution of China's paper industry. J. Clean. Prod. 140, 1105-1117, http://dx.doi.org/10.1016/j.jclepro.2016.10.059/.

Lin, B.Q., Zhao, H., 2016. Technology gap and regional energy efficiency in China's textile industry: a non-parametric meta-frontier approach. J. Clean. Prod. 137, 21-28, http://dx.doi.org/10.1016/j.jclepro.2016.07.055/.

Luo, Z., Gunasekaran, A., Dubey, R., Papadopoulos, T., 2017. Antecedents of low carbon emissions supply chains. Int. J. Clim. Change Strat. Manag. 9 (5), 707-727, http://dx.doi.org/10.1108/IJCCSM-09-2016-0142/.

National Bureau of Statistics of China, 2016. China Statistical Year Book 2011. China Statistics Press, Beijing.

Oh, D.-H., 2010. A global Malmquist-Luenberger productivity index. J. Prod. Anal. 34 (3), 183-197, http://dx.doi.org/10.1007/s11123-010-0178-y/.

Pastor, J.T., Lovell, C.A.K., 2005. A global Malmquist productivity index. Econ. Lett. $88,266-271$.

Saen, R.F., 2007. A new mathematical approach for suppliers selection: accounting for non- homogeneous is important. Appl. Math. Comput. 185 (1), 84-95, http:// dx.doi.org/10.1016/j.amc.2006.07.071/.

Saen, R.F., Memariani, A., Lotfi, F.H., 2005. Determining relative efficiency of slightly non-homogeneous decision making units by data envelopment analysis: a case study in IROST. Appl. Math. Comput. 165 (2), 313-328, http://dx.doi.org/10. 1016/j.amc.2004.04.050/.

Shao, Y., 2017. Analysis of energy savings potential of China's nonferrous metals industry. Res. Conserv. Recycl. 117, 25-33, http://dx.doi.org/10.1016/j. resconrec.2015.09.015/.

Shi, G.M., Bi, J., Wang, J.N., 2010. Chinese regional industrial energy efficiency evaluation based on a DEA model of fixing non-energy inputs. Energy Policy 38 (10), 6172-6179, http://dx.doi.org/10.1016/j.enpol.2010.06.003/.

Song, M.L., An, Q.X., Zhang, W., Wang, Z.Y., Wu, J., 2012. Environmental efficiency evaluation based on data envelopment analysis: a review. Renew. Sustain. Energy Rev. 16 (7), 4465-4469, http://dx.doi.org/10.1016/j.rser.2012.04.052/.

Song, M.L., Wang, S.H., 2017. Measuring environment-biased technological progress considering energy saving and emission reduction. Process Saf. Environ. Prot. 116, 745-753, http://dx.doi.org/10.1016/j.psep.2017.08.042/.

Sueyoshi, T., Goto, M., 2011. Measurement of returns to scale and damages to scale for DEA-based operational and environmental assessment: how to manage desirable (good) and undesirable (bad) outputs? Eur. J. Oper. Res. 211 (1), 76-89, http://dx.doi.org/10.1016/j.ejor.2010.11.013/.

Tapia, J.F.D., Promentilla, M.A.B., Tseng, M.L., Tan, R.M., 2017. Screening of carbon dioxide utilization options using hybrid analytic hierarchy process-data envelopment analysis method. J. Clean. Prod. 165, 1361-1370, http://dx.doi.org/10. 1016/j.jclepro.2017.07.182/.

Tone, K., 2001. A slacks-based measure of efficiency in data envelopment analysis. Eur. J. Oper. Res. 130, 498-509, http://dx.doi.org/10.1016/S03772217(99)00407-5/.

Wang, Q., Zhao, Z., Zhou, P., Zhou, D., 2013. Energy efficiency and production technology heterogeneity in China: a meta-frontier DEA approach. Econ. Model. 35, 283-289, http://dx.doi.org/10.1016/j.econmod.2013.07.017/.

Watanabe, M., Tanaka, K., 2007. Efficiency analysis of Chinese industry: a directional distance function approach. Energy Policy 35, 6323-6331, http://dx.doi.org/10. 1016/j.enpol.2007.07.013/. 